\title{
Trophic Support of Motoneurons: Physiological, Pathophysiological, and Therapeutic Implications
}

\author{
Hans Thoenen, Richard A. Hughes, and Michael Sendtner \\ Department of Neurochemistry, Max Planck Institute for Psychiatry, Am Klopferspitz 18A, D-82152 Martinsried, Germany
}

\section{INTRODUCTION}

Motoneurons played an essential role in establishing the concept that target tissues have an important influence on the development of innervating neurons. In chick embryos, it was demonstrated that the removal of leg or wing buds during early developmental stages resulted in a virtually complete loss of the corresponding motoneurons analyzed at later developmental stages (31). Conversely, the implantation of an additional extremity anlage resulted in an increase of the number of motoneurons projecting into the augmented target area $(31,37)$. The further extension and evaluation of this concept, replacing the physiological target of motoneurons by sarcoma tissue, resulted-by a cascade of lucky coincidences-in the discovery of nerve growth factor (NGF) (summarized in 48), the molecular incarnation of the retrograde trophic influence of peripheral target cells on sympathetic and subpopulations of sensory (both neural crest and placode derived) neurons (summarized in $4,48,104)$.

In contrast to the importance of motoneurons in establishing the concept of the trophic influence of target tissues on innervating neurons, for a long time very little progress was made in identifying molecules responsible for this trophic support. Experimental achievements were confined to the demonstration that skeletal muscle extract or conditioned medium of primary cultures of skeletal muscle myoblasts trophically supported motoneurons in vivo (75) and in vitro $(11,21,24$, $25,57,73,89,99)$.

This situation has changed dramatically within the last few years. Progress was predominantly determined by an improvement of the motoneuron cell culture procedures $(3,10,12,33,34,39)$ and the identification of neurotrophic molecules in adult and/or embryonic skeletal muscles with already known neurotrophic actions on other populations of neurons in vitro and in vivo (3, $13,34,36,38,39,45,54,58,80)$. The importance of appropriate culture systems for motoneurons is demonstrated by the fact that, for a long time, no single, defined molecule could be demonstrated to have a convincing trophic action on motoneurons. Even molecules like CNTF, which have been shown later to have a distinct survival effect in vitro and in vivo on motoneurons, were initially reported to have no effect on mixed spinal cord cultures of the chick (51). Now we have a large number of molecules which show such effects, and it is the goal of present and future investigations to elucidate their (relative) physiological role during different stages of development, their possible pathophysiological importance, and, as a consequence, their suitability for the treatment of degenerative diseases of motoneurons such as amyotrophic lateral sclerosis (ALS) which, so far, are not amenable to any therapy $(88,102)$. In this context, it should be emphasized that, according to currently available information, there is not a single human or animal degenerative disease of the nervous system which can causally be linked to an insufficient or false (mutated) production of neurotrophic molecule (98). However, neurotrophic molecules have been demonstrated to rescue specific neurons from the consequences of a variety of mechanical (axotomy) or chemical (6-hydroxydopamine, MPTP, excitotoxic amino acids) damages $(40,45,50,79,93,96,104,107)$. Therefore, the use of neurotrophic molecules in the treatment of degenerative diseases of the nervous system is a symptomatic one and strongly encourages further investigations aimed at a molecular understanding of the pathogenetic mechanisms of degenerative disorders of the nervous system.

In the following, we give a brief survey of the molecules with an established action on motoneurons (in vitro and/or in vivo) and the present and potential future approaches to the elucidation of the relative physiological and pathophysiological importance of these molecules. Finally, we discuss the essential criteria to be considered for a rational evaluation of neurotrophic molecules in the treatment of degenerative disease of the nervous system, in general, and of motoneuron disorders, in particular.

\section{CILIARY NEUROTROPHIC FACTOR (CNTF) AND RELATED MOLECULES}

CNTF was originally identified and partially purified as a target-derived neurotrophic factor for parasympa- 
thetic cholinergic neurons of the chick ciliary ganglion (1, 32, 69). Further investigations demonstrated that CNTF had a much broader spectrum of action in vitro, including survival effects on sympathetic, sensory, and, more recently, hippocampal, locus coeruleus, and dopaminergic mesencephalic neurons $(30,41,52,53,94)$.

In the course of investigations aimed at the identification and purification of trophic factors for motoneurons in extracts of adult skeletal muscle, a marked motoneuron survival activity, eluted from preparative gels, had physicochemical properties corresponding to those of CNTF isolated from the rat sciatic nerve (Sendtner, unpublished observations). The results obtained with this enriched preparation could later be confirmed by CNTF purified to homogeneity and recombinant CNTF $(3,59,93,94)$.

For embryonic chick motoneurons in culture, CNTF has been shown to be the most potent neurotrophic molecule thus far characterized, displaying half-maximal survival at a concentration of $30 \mathrm{pg} / \mathrm{ml}$ with a maximal survival effect of over $60 \%$ of the originally plated motoneurons (3). Similar positive effects have also been observed in vivo when CNTF was administered onto the chorioallantoic membrane of chick embryos at the same developmental stages $(70,77)$. That CNTF has a direct action on motoneurons could be deduced from the fact that the survival effect in single motoneuron cultures was identical to that in $80 \%$ pure low-density cultures (94). The cloning of CNTF was the prerequisite for producing large quantities of recombinant CNTF (49, 59, 100) and for the determination of its developmental expression and cellular localization (20, 27, 86, 94, 97, 100, 101). These investigations demonstrated that CNTF is expressed postnatally in myelinating Schwann cells (27, $86,97,100,101)$ and a subpopulation of type I astrocytes $(20,101)$ in the CNS, that CNTF is a cytosolic molecule, and that the biological activity, e.g., in the adult sciatic nerve, is more than 10,000 times higher than that of (retrogradely) transported NGF in the rat sciatic nerve $(35,97,98)$.

The time course of the developmental expression of $\mathrm{CNTF}$ and its subcellular localization precluded a function of CNTF as a molecule regulating the survival of motoneurons during embryonic development, which takes place between E15 and P1 in rats (74). However, the time period of natural motoneuron cell death is followed by an augmented sensitivity to axonal damage. At birth, axotomy of motoneurons results in a virtually complete degeneration of the corresponding neuronal cell bodies $(90,93)$. This effect gradually decreases with increasing age. Since there is a striking reciprocity between the postnatal reduction in the sensitivity of motoneurons to axotomy and the developmental increase in CNTF expression in myelinating Schwann cells, we put forward the working hypothesis that CNTF might act as a "lesion factor." Indeed, the local administration of
CNTF after transection of the facial nerve in newborn rats virtually completely prevented the degeneration of the motoneuron cell bodies (93). Moreover, in adult animals, in spite of the reduction of the CNTF mRNA after transection of the sciatic nerve, the CNTF-assigned biological activity in the peripheral part of the sciatic nerve undergoing Wallerian degeneration was still about 1000 times higher than the amount of "reactively" enhanced synthesis of NGF by nonneuronal sciatic cells 1 week after lesion $(35,97,98)$. Certainly, CNTF is not the sole factor responsible for motoneuron regeneration in peripheral nerves. The reactive synthesis of BDNF occurring with a delay of about 7 days after axotomy (63) also shows features which are compatible with a supportive role of BDNF for the regrowth of axons to the periphery, taking over from the "first aid" function of CNTF.

Very recent experiments with pmn mutant mice have provided further strong evidence for the function of CNTF as a lesion factor. Pmn mice show a strictly programmed, progressive degeneration of motoneurons starting at the hind legs, progressing to the forelegs, and finally also affecting the motor nuclei of the brain stem, including the facial motor nucleus $(91,95)$. The transection of the facial nerve in pmn mice 2 weeks after the first clinical signs of motoneuron degeneration (hind legs) did not result in an enhanced but a delayed progression of facial motoneuron degeneration. Interestingly, in pmn mice crossbred with CNTF null mutants, the facial nerve lesion no longer resulted in a delay of facial motoneuron degeneration (Sendtner, unpublished results).

Given that CNTF is expressed only postnatally and that it is a cytosolic molecule $(100,101)$, the question arose as to whether CNTF functions only under pathophysiological conditions where, after nerve lesion, it might be released from its cytosolic site of production, or whether CNTF also has a physiological function resulting from the release of CNTF from the cytosol either by repetitive microtrauma or by a non-ER-Golgi unconventional release mechanism involving only a very small proportion of the cytosolic CNTF. To address this issue, we used gene-targeting techniques to produce transgenic mice in which the CNTF gene was disrupted (60). As expected, CNTF null mutants obtained by gene targeting resulting in a complete absence of CNTF protein and corresponding biological activity did not show a reduction of the number of motoneurons during embryonic development (60). Also during the first postnatal weeks, there was no evidence for atrophic or degenerative changes in motoneurons. However, morphometric analysis of spinal motoneurons demonstrated a gradually increasing atrophy and degeneration of motoneurons accompanied by reactive gliosis, starting at the eighth postnatal week. By 28 weeks, a $22 \%$ reduction of the number of motoneurons in the facial nucleus was detectable (60). Although the motor func- 
tion from plain inspection did not indicate clear-cut signs of motoneuron impairment, measurement of grip strength as a parameter for motor function revealed a small but statistically significant reduction in 28 -weekold CNTF null mutants (60). The fact that the clinical manifestation of impaired function in degenerative motoneuron diseases does not occur before $50 \%$ of the motoneurons have degenerated (67) and the statistically significant $(P<0.05)$ reduction in grip strength not only reflects the number of neurons lost but also an impaired function of at least part of the atrophic motoneurons. It has not yet been established whether the atrophic degenerative processes will further continue or whether the process will stabilize, possibly due to compensatory enhanced production of other neurotrophic molecules coming into play, such as the reactive increase in BDNF formation observed after lesion of the sciatic nerve (63). Thus, the available information permits the conclusion that CNTF has a distinct, although not exclusive, maintenance function for motoneurons in the postnatal phase, whereby the question of the mechanism of release from the cytosolic compartment remains unresolved.

The predicted three-dimensional structures of CNTF, LIF, interleukin-6, and oncostatin-M (7)-in spite of the absence of significant sequence homologies - show common structural features which are also reflected by common signal-transducing units in the corresponding receptors (for review, see 42, 103). CNTF, LIF, and interleukin-6 share a common signaltransducing unit, gp 130, which is complemented by specific binding units. The intracellular domain of the LIF binding unit shares sequence homology with gp130. Interestingly, in addition to its (low affinity) GPI-linked binding unit (17), CNTF needs not only gp130 but also the LIF low-affinity binding unit for signal transduction $(5,42)$. Thus, LIF, interleukin-6, and oncostatin-M deserve a thorough evaluation as additional potential neurotrophic molecules for motoneurons. Indeed, in vitro and in vivo effects of LIF on motoneurons have been observed $(34,39,58)$. However, the physiological relevance of these observations remains to be established, particularly in view of the fact that a first evaluation of LIF $-/-$ mice did not show any changes in spinal motoneurons either at the morphological or functional levels (84).

\section{NEUROTROPHIC EFFECTS OF THE MEMBERS OF THE FIBROBLAST GROWTH FACTOR (FGF) GENE FAMILY}

In the same culture system of embryonic (E6) chick motoneurons in which the potent effects of CNTF were established, basic FGF (bFGF) demonstrated the second-best survival effect both with respect to the extent (50\% survival) and the half-maximal concentration
(280 pg/ml). The effects of CNTF and bFGF were largely additive, their combination resulting in a longterm $100 \%$ survival of chick embryonic motoneurons in culture (3). bFGF is broadly expressed in many embryonic tissues (28). However, because bFGF is not released according to the ER-Golgi secretory pathway and the mechanism(s) of a potential unconventional release is not known, bFGF is not a promising candidate for the regulation of motoneuron survival during embryonic development. However, another member of the FGF gene family, FGF-5, seems to fulfill the prerequisites for a target-derived trophic factor for motoneurons. FGF-5 shows a potent survival effect on both chick and rat motoneurons $(38,39)$. It is expressed in rat skeletal muscle from E15 to adulthood. Using an antiserum raised against a peptide from the C-terminus of FGF-5, which was able to precipitate recombinant FGF-5, 40$50 \%$ of the survival activity present in embryonic rat skeletal muscle extract could be immunoprecipitated. In adult rat skeletal muscle the FGF-5-assigned survival activity was strongly matrix-bound and could only be released by high salt and EDTA (38). The relative contribution of FGF-5 to the survival effect of rat skeletal muscle extract should be judged with caution, as cultured chick embryonic motoneurons were used as an assay, and these cultures do not respond to any of the neurotrophins tested so far (3) (see below). Conversely, it has also to be emphasized that the potency of FGF-5 in rat embryonic motoneuron cultures is about 10 times higher than in the corresponding cultures of chick motoneurons (39).

\section{NEUROTROPHIC EFFECTS OF MEMBERS OF THE NGF GENE FAMILY}

In the initial in vitro investigations with chick motoneurons no survival effect of any available member of the NGF gene family, even at very high concentrations, could be detected $(3,10)$. However, when it became apparent that the mRNAs of BDNF, NT-3, and NT-4/5 are expressed in rat skeletal muscle during embryonic development and also adulthood $(9,36,55)$, that the signal-transducing units mediating the effects of BDNF, NT-3, and NT-4/5, namely trkB and trkC, are expressed by motoneurons $(26,34)$, and that the specific retrograde axonal transport of labelled BDNF and NT3 was demonstrated (18), a reevaluation of the negative results obtained in vitro with chick motoneurons was mandatory. Indeed, independently four laboratories demonstrated an in vivo effect of BDNF on motoneurons $(45,78,96,107)$. The administration of recombinant BDNF on the chick embryo chorioallantoic membrane resulted in an increased survival of spinal motoneurons (78) and, in newborn rats, the loss of motoneurons following lesion (sciatic or facial nerve) could be prevented by the local administration of recombinant BDNF $(45,96,107)$. Moreover, in the facial 
nerve lesion paradigm, also NT-3 was found to have a rescue effect which, however, was smaller than that of BDNF (96). Very recently, a neuron rescue effect has also been observed in lesioned facial motoneurons after the administration of NT-4 (39). These in vivo effects have been complemented by the observation of survival effects of BDNF, NT-3, and NT-4/5 in vitro in rat motoneurons $(34,39)$. Consistently, under all in vitro and in vivo experimental conditions, no survival or rescue effect of NGF could be demonstrated $(3,10,34,39,65,96$, $107)$, which is also in agreement with the absence of detectable expression of $\operatorname{trkA}(34,56)$, the signal-transducing receptor unit of NGF. On the contrary, there is experimental evidence that NGF even enhances the degeneration of motoneurons and interferes with the survival action of other members of the NGF gene family in vitro and in vivo $(39,65,96)$.

\section{INSULIN-LIKE GROWTH FACTOR (IGF-I)}

The survival promoting effect of IGF-I in chick motoneurons in culture is very modest and only detectable at high concentrations ( $15 \%$ survival at $1 \mu \mathrm{g} / \mathrm{ml}$ ) (3). In more recent experiments with rat motoneurons, a marked neurotrophic action of IGF-I has been observed, the maximal survival amounting to $50 \%$ at the halfmaximal concentration of $500 \mathrm{pg} / \mathrm{ml}$ (39). Moreover, IGF-I also exhibits a marked rescue effect in the newborn rat facial nerve lesion paradigm (39).

The very drastic difference between the survival effects of IGF-I in chick compared to rat motoneurons in culture was due, most likely, to the different culture conditions. The culture medium used for chick motoneurons contains horse serum (3) which has been shown to contain substantial amounts of IGF-I-binding proteins (83) which neutralize the biological activity of IGF-I. It has been established that IGF-I is expressed by embryonic and adult skeletal muscle $(14,105)$, that its levels increase after skeletal muscle denervation (14), and that IGF-I exhibits an essential sprouting activity on motoneurons in vivo (13). The relative physiological role of IGF-I as a neurotrophic molecule during embryonic development, and possibly also as a maintenance factor in adulthood, requires a careful evaluation together with the role of the increasing number of IGFbinding proteins (6) which, at least partially, are coregulated with IGF-I (46) and might play an important role in restricting the area of action of IGF-I and limit systemic actions such as hypoglycemia and general growth (see Lewis et al. (48a), this issue).

DISCORDANT RESULTS ORIGINATING FROM SPECIES DIFFERENCES AND DIFFERING CULTURE CONDITIONS: DISCREPANCIES BETWEEN IN VIVO AND IN VITRO EFFECTS

The rapidly increasing number of molecules which exhibit neurotrophic actions on motoneurons has also left us with a series of discordant findings which, at least for the in vitro observations, can be explained by differences in the culture conditions (e.g., serum vs serumfree medium), the preparation and selection of motoneurons, the "time window" selected for the preparation of motoneurons, and also by species differences $(3,10,23$, $24,33,34,39,68)$. Moreover, there are substantial discrepancies between in vitro and in vivo effects for given molecules. The elucidation of the reasons for these discordant results is not only of importance for the elucidation of the relative-if any-physiological importance of the different molecules for the regulation of the embryonic survival of motoneurons and their differentiation and maintenance in adulthood, but also with respect to the potential use of these molecules for the treatment of traumatic and/or degenerative disorders of motoneurons. As it is impossible to discuss all of the details of discordant, or apparently discordant, results, we confine the discussion to a few aspects which are of potential importance with respect to the use of these molecules for the treatment of neurodegenerative diseases.

In initial experiments, Henderson and co-workers, using a panning method for the isolation of chick motoneurons, could not detect a survival effect of either CNTF and bFGF $(10,33)$. The method used had the advantage that it provided a virtually $100 \%$ pure population of chick motoneurons. However, the epitope recognized by the monoclonal antibody used for the panning procedure is only expressed up to E4.5 and therefore restricted the time period available for the analysis. In contrast, Arakawa and co-workers (3) used, from the point of view of the purity, a less ideal procedure permitting the selection of an $80 \%$ pure population of motoneurons at E6, the beginning of the physiological death period of chick embryo motoneurons. After this isolation and selection procedure, a very marked, potent survival effect of CNTF became apparent (3). This discrepancy could be explained by the preparation of the neurons, e.g., the protease concentrations used damaging the $\mathrm{CNTF}$ receptor, but leaving intact the SCI-epitope used for the panning procedure. Alternatively, at E4.5, the CNTF signal-transducing multiunit receptor complex might not yet be expressed in contrast to E6. A similar argumentation could be used for the complete lack of effect of all members of the neurotrophin gene family analyzed in E6 chick embryo motoneuron cultures (3). Again, it could well be that the isolation procedure used could have damaged the corresponding trk receptors but not the CNTF receptor complex or, at E-6, the relevant functional trk receptors are not yet present on motoneurons. Indeed, after an initial maintenance period with CNTF a switch to BDNF or NT-3 revealed a distinct survival effect of these two members of the NGF gene family (Hughes, unpublished results). In contrast to chick motoneurons, E-15 rat embryonic 
motoneurons showed a very marked response to BDNF, NT-3, and NT-4/5 $(34,39)$. Conversely, the survival effect of CNTF in these rat motoneurons was distinctly below the effects observed in chick motoneurons $(3,34$, 39). The argumentations for the discrepancies are the same as those brought forward for the lacking effect of the members of the NGF gene family in chick motoneurons.

Of particular interest is the complete discrepancy between the effects of FGFs (both bFGF and FGF-5) in vitro and in vivo $(3,38,39,70,76)$. For example, in contrast to the strong survival effects in vitro (both in chick and rat motoneuron cultures), both molecules were without protective effect against motoneuron degeneration after lesioning of the newborn rat facial nerve (39). The amounts of locally administered bFGF and FGF-5 corresponded to those of CNTF, BDNF, NT-3, NT-4, IGF-I, and LIF which showed a clear-cut, although differing, rescue effect $(39,45,93,94)$. The limited amounts of available recombinant FGF-5 did not permit experiments with excessively high quantities of recombinant FGF-5 as, for example, used for the demonstration of the protective effect of BDNF in the lesioned newborn rat sciatic nerve (107). Also in chick embryos administered to the chorioallantoic membrane, bFGF had no neurotrophic action on motoneurons $(70,76)$, although it had a distinct mitogenic effect on other cell populations, excluding the possibility that bFGF was trapped by heparin-like molecules and prevented from reaching the site of action, i.e., motoneurons. However, very recently, Nurcombe and co-workers (71) demonstrated that when aFGF was administered to the chorioallantoic membrane of chick embryos as a complex with a specific heparan sulfate proteoglycan (72), a distinct neurotrophic effect on motoneurons could be observed (71). This would indicate that the essential complementary proteoglycan necessary for the signal transduction via the corresponding FGF receptor is present on cultivated FGF-responsive neurons, whereas it is not expressed in vivo. Tissue-specific expression of such proteoglycans might be responsible for the positive survival effects of bFGF on lesioned hypoglossal motoneurons in vivo (29), which are in disagreement with the negative effects observed by other investigations after in vivo administration of bFGF onto the chorioallantoic membrane of the chick embryo $(70,76)$.

The elucidation of the discrepancies between in vitro and in vivo effects is essential not only with respect to understanding the importance of individual neurotrophic molecules for the trophic support of motoneurons during different developmental stages, but also to the crucial importance for the decision as to whether these molecules should be considered for therapeutic use in humans. Current and future experiments designed to elucidate the physiological function of the different molecules include the abolition of their expression by gene targeting, as described above for CNTF, by tissue (neuron or muscle)-specific overexpression in transgenic animals, and by the reduction of expression using antisense mRNA procedures and the systemic and/or local administration of blocking antibodies. Of particular interest in the framework of the use of antibodies is the transgenic expression of specific antibodies under the control of a tissue-specific promoter (81), particularly when combined with a regulatory sequence which permits the turning on or off of the antibody production.

\section{CRITERIA FOR SELECTING NEUROTROPHIC MOLECULES FOR CLINICAL TRIALS}

Because the use of neurotrophic molecules for the treatment of degenerative diseases of motoneurons represents a symptomatic rather than causal therapy, it is essential to collect information on the variety of models which could be of relevance for the human degenerative disorders. These include protection of motoneurons against lesion effects and protective effects on the progression of degenerative changes in animal mutants such as the pmn mouse (91), which exhibits characteristics similar to ALS (15), the mnd mouse $(61,62)$, and the wobbler mutant $(22,43,82)$, in which the paretic manifestations become apparent predominantly in the forelegs and do not reach levels as extreme as those in the case of the pmn mutant (91). Very recently, transgenic mice with a neuron-specific overexpression of light and heavy neurofilament chains have been created $(16,106)$ which show morphological changes of myelinating axons with similarities to the pathological picture of ALS patients (15). The impaired motoneuron function seems to result from an impairment of axonal transport $(16,106)$. The evaluation of the neurotrophic molecules considered for clinical trials in all these animal models will be of interest, and the observations made there will be of particular importance for future investigations as soon as the first clinical results, which are underway for CNTF (Lindsay et al. (50a), this issue) and IGF-I (Lewis et al. (48a) this issue), can be compared with the effects of these molecules in animal models.

\section{CRITERIA FOR THE EVALUATION OF NEUROTROPHIC MOLECULES IN ANIMAL MODELS AND CLINICAL TRIALS}

In vitro and in vivo experiments have demonstrated that, in order to exhibit their protective effect, neurotrophic factors have to be present continuously. Therefore, in order to evaluate the effects of neurotrophic molecules, both in animal models and in clinical trials, it is essential, at least for the initial evaluation of whether the neurotrophic factor has the desired effect, that a constant level of the neurotrophic molecule at the site of action is accomplished. Although the technical invest- 
ments to reach this goal are distinctly higher than those for the administration of neurotrophic molecules by bolus injection, it has to be remembered that, for example, the half-time of CNTF if injected intravenously is 4 min (19). In this case, the main clearing site is the liver which is also the site of the most essential unwanted side effects, i.e., induction of acute phase proteins like haptoglobin and fibrinogen $(5,19,92,98)$. In many cases, the effects of neurotrophic molecules on motoneuron survival are additive $(3,39)$ and since the potential side effects of the different molecules, particularly of different gene families, are different, a combination of different neurotrophic molecules for the treatment of degenerative diseases should be envisaged under the aspect that, by their combination, a better ratio between the neurotrophic support and (unwanted) side effects could possibly be obtained.

\section{FUTURE PERSPECTIVES FOR THE TREATMENT OF DEGENERATIVE DISORDERS OF MOTONEURONS}

A more detailed understanding of the signal-transduction mechanism(s) evolving from the interaction of neurotrophic molecules with their receptors and a better understanding of the reasons why neurotrophic factors exhibit a general neuroprotective action against a variety of mechanical and chemical damages to neurons would open up new possibilities for a more focussed pharmacological modification of the cascade of signal transduction. First steps in these directions have very recently been made by synthesizing low molecular compounds which modify, in a more or less specific manner, the tyrosine kinase activity of the trk receptor family (44) (see also Hempstead (32a), this issue). Conversely, an understanding of the molecular mechanisms responsible for the pathological changes in human motoneuron diseases $(2,8,47,88)$ would permit a more selective choice of animal models for preclinical investigations. For the time being, one is left with a simple empirical approach, comparing the effects in animal models with the results of clinical investigations from case to case for individual neurotrophic molecules. Moreover, an understanding of the molecular mechanisms responsible for the degenerative disorders would also possibly open up new, more direct therapeutic approaches which interfere directly with the pathogenetic mechanism. The first promising indications in this direction have evolved from very recent reports indicating that, in a fraction of familial ALS cases (which represent about $5 \%$ of all ALS patients), there are mutations in the superoxide dismutase gene (87). However, it is not yet clear whether these mutations lead to an enhanced or reduced activity of the enzyme (87). Both an augmentation of the superoxide radical, in the case of reduced activity of superoxide dismutase, and the enhanced formation of $\mathrm{H}_{2} \mathrm{O}_{2}$, in the case of augmented enzyme activ- ity, could result in neuronal damage (reviewed in 47 and 64),

The fact that there are distinct discrepancies between the in vitro and in vivo effects of neurotrophic molecules, particularly the lack of effect of all members of the FGF gene family in vivo $(39,70,76)$ compared to their efficacy in vitro $(3,38,39)$, raises the question of whether these molecules would need to be administered as a complex with an appropriate heparan sulfate glycoprotein $(71,72)$ or whether better effects could be obtained by the direct local administration, e.g., by direct gene transfer into the muscle (85), by engineering of (autologous) myoblasts in culture and their reimplantation, or by the use of viral systems (see 66). The approaches delineated here for the gene transfer into skeletal muscle could also be used for the local administration in peripheral nerves, such as the use of engineered autologous Schwann cells, and also in the spinal cord, as an alternative to the intrathecal infusion of neurotrophic molecules. This approach could be very useful for situations in which factors are unable to exert the desired effects on motoneurons from the periphery, either because the corresponding receptors on nerve terminals or axons are damaged or because the signal-transduction mechanisms including retrograde transport are also impaired by the pathological disturbance.

\section{ACKNOWLEDGMENTS}

We are grateful to Regeneron Pharmaceuticals (Tarrytown, NY) for supplying us with recombinant CNTF, BDNF, and NT-3 and to Mitchell Goldfarb (Department of Biochemistry and Molecular Biophysics, College of Physicians and Surgeons, Columbia University, New York, NY) for supplying us with recombinant FGF-5. Richard A. Hughes is a fellow of the Humboldt Foundation. We are particularly grateful to Ingrid Hajjar for linguistic revisions and secretarial help.

\section{REFERENCES}

1. Adler, R., K. B. Landa, M. Manthorpe, and S. Varon. 1979. Cholinergic neurotrophic factors: intraocular distribution of trophic activity for ciliary neurons. Science 204: 1434-1436.

2. Appel, S. H. 1993. Excitotoxic neuronal cell death in amyotrophic lateral sclerosis. Trends Neurosci. 16: 3-4.

3. Arakawa, Y., M. Sendtner, and H. Thoenen. 1990. Survival effect of ciliary neurotrophic factor (CNTF) on chick embryonic motoneurons in culture: Comparison with other neurotrophic factors and cytokines. J. Neurosci. 10, 3507-3515.

4. BARDE, Y.-A. 1989. Trophic factors and neuronal survival. Neuron 2: 1525-1534.

5. Baumann, H., S. F. Ziegler, B. Mosley, K. K. Morella, S. PAJOVIC, AND D. P. GEARING. 1993. Reconstitution of the response to leukemia inhibitory factor, oncostatin-m, and ciliary neurotrophic factor in hepatoma-cells. J. Biol. Chem. 268: 8414-8417.

6. BAXter, R. C., AND J. L. MARTin. 1989. Binding proteins for the insulin-like growth factors: Structure, regulation and function. Prog. Growth Factor Res. 1: 49-68. 
7. BAZAN, J. F. 1991. Neuropoietic cytokines in the hematopoietic fold. Neuron 7: 197-208.

8. Beal, M. F., B. T. Hyman, and W. Koroshetz. 1993. Do defects in mitochondrial energy metabolism underlie the pathology of neurodegenerative diseases? Trends Neurosci. 16: 125131.

9. Berkemeier, L. R., J. W. Winslow, D. R. Kaplan, K. NikoLICS, D. V. Goeddel, AND A. Rosenthal. 1991. Neurotrophin5: A novel neurotrophic factor that activates trk and trkB. Neuron 7: 857-866.

10. Bloch-Gallego, E., M. Huchet, H. El M'hamdi, F.-K. Xie, H. TANAKA, AND C. E. Henderson. 1991. Survival in vitro of motoneurons identified or purified by novel antibody-based methods is selectively enhanced by muscle-derived factors. $D e$ velopment 111: 221-232.

11. Calof, A. L., and L. F. Reichardt. 1984. Motoneurons purified by cell sorting respond to two distinct activities in myotube-conditioned medium. Dev. Biol. 106: 194-210.

12. Camu, W., AND C. E. Henderson. 1992. Purification of embryonic rat motoneurons by panning on a monoclonal antibody to the low-affinity NGF receptor. J. Neurosci. Methods 44: 59-70.

13. Caroni, P., AND P. Grandes. 1990. Nerve sprouting in innervated adult skeletal muscle induced by exposure to elevated levels of insulin-like growth factors. J. Cell Biol. 110: 13071313.

14. Caroni, P., AND M. Becker. 1992. The downregulation of growth-associated proteins in motoneurons at the onset of synapse elimination is controlled by muscle activity and IGF-1. J. Neurosci. 12: 3849-3861.

15. CHou, S. M. 1992. Pathology-light microscopy of amyotrophic lateral sclerosis. In Handbook of Amyotrophic Lateral sclerosis (R. A. Smith, Ed.), pp. 133-182. Dekker, New York.

16. Côté, F., J.-F. Collard, AND J.-P. Julien. 1993. Progressive neuronopathy in transgenic mice expressing the human neurofilament heavy gene: A mouse model of amyotrophic lateral sclerosis. Cell 73: $35-46$.

17. Davis, S., T. H. Aldrich, D. M. Valenzuela, V. Wong, M. E. Furth, S. P. Squinto, AND G. D. Yancopoulos. 1991. The receptor for ciliary neurotrophic factor. Science 253: 59-63.

18. DiStefano, P. S., B. Friedman, C. Radziejewski, C. AlexANDER, P. Boland, C. M. SCHICK, R. M. Lindsay, AND S. J. WIEGAND. 1992. The neurotrophins BDNF, NT-3, and NGF display distinct patterns of retrograde axonal transport in peripheral and central neurons. Neuron 8: 983-993.

19. Dittrich, F., H. Thoenen, And M. Sendtner. 1993. Ciliary neurotrophic factor: Pharmakokinetics and acute phase response. Ann. Neurol., in press.

20. Dobrea, G. M., J. R. Unnerstall, and M. S. Rao. 1992. The expression of CNTF message and immunoreactivity in the central and peripheral nervous system of the rat. Dev. Brain Res. 66: 209-219.

21. Dohrmann, U., D. Edgar, M. Sendtner, and H. Thoenen. 1986. Muscle-derived factors that support survival and promote fiber outgrowth from embryonic chick spinal motor neurons in culture. Deu. Biol. 118: 209-221.

22. Duchen, L. W., AND S. J. STRICH (with an Appendix by D. S. Falconer). 1968. An hereditary motor neurone disease with progressive denervation of muscle in the mouse: The mutant "wobbler." J. Neurol. Neurosurg. Psychiat. 31: 535-542.

23. Eagleson, K. L., T. R. Raju, and M. R. Bennett. 1985. Motoneurone survival is induced by immature astrocytes from developing avian spinal cord. Dev. Brain Res. 17: 95-104.

24. Eagleson, K. L., AND M. R. Bennet. 1986. Motoneuron survival factor requirements during development: The change from immature astrocyte dependence to myotube dependence. Dev. Brain. Res. 28: 161-172.

25. Flanigan, T. P., J. G. Dickson, and F. S. Walsh. 1985. Cell survival characteristics and choline acetyl transferase activity in motoneuron-enriched cultures from chick embryo spinal cord. J. Neurochem. 45: 1323-1326.

26. Ernfors, P., C. M. Rosario, J. P. Merlio, G. Grant, H. Aldskogius, AND H. PERsson. 1993. Expression of messenger $R N A$ s for neurotrophin receptors in the dorsal root ganglion and spinal cord during development and following peripheral or central axotomy. Mol. Brain Res. 17: 217-226.

27. Friedman, B., S. S. Scherer, J. S. Rudge, M. Helgren, D. Morrisey, J. McClain, Wang, S. J. Wiegand, M. E. Furth, R. M. LINDSAY, AND N. Y. IP. 1992. Regulation of ciliary neurotrophic factor expression in myelin-related Schwann cells in vivo. Neuron 9: 295-305.

28. Gonzalez, A.-M., M. Buscaglia, M. Ong, and A. Baird. 1990. Distribution of basic fibroblast growth factor in the 18-day rat fetus: localization in the basement membranes of diverse tissues. J. Cell Biol. 110: 753-765.

29. Grothe, C., AND K. UNSicker. 1992. Basic fibroblast growth factor in the hypoglossal system-specific retrograde transport, trophic and lesion-related responses. J. Neurosci. Res. 32: 317328.

30. Hagg, T., D. Quon, J. Higaki, AND S. VARon. 1992. Ciliary neurotrophic factor prevents neuronal degeneration and promotes low affinity NGF receptor expression in the adult rat CNS. Neuron 8: 145-158.

31. Hamburger, V. 1958. Regression versus peripheral control of differentiation in motor hyperplasia. Am. J. Anat. 102: 365410.

32. Helfand, S. L., G. A. Smith, AND N. K. Wessells. 1976. Survival and development in culture of dissociated parasympathetic neurons from ciliary ganglia. Dev. Biol. 50: 541-547.

32a. Hempstead, B. L. 1993. Strategies for modulating Trk receptor activity. Exp. Neurol. 124: 31-35.

33. Henderson, C. E., E. Bloch-Gallego, W. Camu, A. Gouin, AND C. Metruing. 1993. Neurotrophic factors in development and plasticity of spinal neurons. Restor. Neurol. Neurosci. 5: 15-28.

34. Henderson, C. E., W. Camu, C. Metrling, A. Gouin, K. Poulsen, M. Karihaloo, J. Rullamas, T. Evans, S. B. Mcmahon, M. P. Armanini, L. Berkemeier, H. S. Phillips, AND A. Rosenthal. 1993. Neurotrophins promote motor neuron survival and are present in embryonic limb bud. Nature 363: 266-270.

35. Heumann, R., S. Korsching, C. Bandtlow, and H. THOENEN. 1987. Changes of nerve growth factor synthesis in non-neuronal cells in response to sciatic nerve transection. $J$. Cell Biol. 104: 1623-1631.

36. Hohn, A., J. Leibrock, K. Bailey, and Y.-A. Barde. 1990. Identification and characterization of a novel member of the nerve growth factor/brain-derived neurotrophic factor family. Nature 344: 339-341.

37. Hollyday, M., AND V. Hamburger. 1976. Reduction of the naturally occurring motor neuron loss by enlargement of the periphery. J. Comp. Neurol. 170: 311-320.

38. Hughes, R. A., M. Sendtner, M. Goldfarb, D. Lindholm, AND H. Thoenen. 1993. Evidence that fibroblast growth factor 5 is a major muscle derived survival factor for cultured spinal motoneurons. Neuron 10: 369-377.

39. Hughes, R. A., M. Sendtner, And H. Thoenen. 1993. Representatives of several gene families influence survival of rat motoneurons in vitro and in vivo. J. Neurosci. Res., in press. 
40. Hyman, C., M. Hofer, Y.-A. Barde, M. Juhasz, G. D. Yancopoulos, S. P. SQuinto, AND R. M. LindSAy. 1991. BDNF is a neurotrophic factor for dopaminergic neurons of the substantia nigra. Nature 350: 230-232.

41. IP, N. Y., Y. Li, I. Van de Stadt, N. Panayotatos, R. F. AlDERSON, AND R. M. LINDSAY. 1991. Ciliary neurotrophic factor enhances neuronal survival in embryonic rat hippocampal cultures. J. Neurosci. 11: 3124-3134.

42. IP, N. Y., AND G. D. YANCOPOULOS. 1993. Ciliary neurotrophic factor and its receptor complex. Prog. Growth Factor Res. 4: 139-155.

43. Kaupmann, K., D. Simon-Chazottes, J. L. Guenet, and H. JoCKUSCH. 1992. Wobbler, a mutation affecting motoneuron survival and gonadal functions in the mouse, maps to proximal chromosome-11. Genomics 13: 39-43.

44. KNÜSEL, B., AND F. HeFti. 1992. K-252 compounds: Modulators of neurotrophin signal transduction. J. Neurochem. 59(6): 1987-1996.

45. Koliatsos, V., R. E. Clatterbuck, J. W. Winslow, M. H. Cayouette, And D. L. Price. 1993. Evidence that brain-derived neurotrophic factor is a trophic factor for motor neurons in vivo. Neuron 10: 359-367.

46. Lee, W. H., S. Javedan, And C. A. Bondy. 1992. Coordinate expression of insulin-like growth factor system components by neurons and neuroglia during retinal and cerebellar development. J. Neurosci. 12: 4737-4744.

47. LEES, G. J. 1993. Contributory mechanisms in the causation of neurodegenerative disorders. Neuroscience 54: 287-322.

48. Levi-Montalcini, R. 1987. The nerve growth factor: Thirtyfive years later. $E M B O$ J. 6: 1145-1154.

48a. Lewis, Neff, Contreras, Stong, Grebow, and Vaught. 1993. Insulin-like growth factor I: Potential for treatment of motor neuronal disorders. Exp. Neurol. 124: 73-88.

49. Lin, L.-F. H., D. Mismer, J. D. Lile, L. G. Armes, E. T. Butler, III, J. L. VANNICE, AND F. Collins. 1989. Purification, cloning and expression of ciliary neurotrophic factor (CNTF). Science 246: 1023-1025.

50. Lindholm, D., G. Dechant, C.-P. Heisenberg, and H. THOENEN. 1993. Brain-derived neurotrophic factor (BDNF) is a survival factor for cultured rat cerebellar granule neurons and protects them against gluatamate-induced neurotoxicity. Eur. J. Neurosci., in press.

50a. Lindsay, Altar, Cedarbaum, Hyman, And Wiegand. 1993. The therapeutic potential of neurotrophic factors in the treatment of Parkinson's disease. Exp. Neurol. 124: 103-118.

51. Longo, F. M., M. Manthorpe, And S. VARon. 1982. Spinal cord neurotrophic factors (SCNTFs). I. Bioassay of Schwannoma and other conditioned media. Dev. Brain Res. 3: 277-294.

52. Louis, J. C., E. Magal, P. Burnham, and S. Varon. 1993. Cooperative effects of ciliary neurotrophic factor and norepinephrine on tyrosine hydroxylase expression in cultured rat locus-ceruleus neurons. Dev. Biol. 155: 1-13.

53. Magal, E., P. Burnham, S. Varon, and J. C. Louis. 1993. Convergent regulation by ciliary neurotrophic factor and dopamine of tyrosine hydroxylase expression in cultures of rat substantia-nigra. Neuroscience 52: 867-881.

54. Maisonpierre, P. C., L. Belluscio, S. Squinto, N. Y. IP, M. E. Furth, R. M. LindSAY, AND G. D. YanCopoulos. 1991. Neurotrophin-3: A neurotrophic factor related to NGF and BDNF. Science 247: 1446-1451.

55. Maisonpierre, P. C., L. Belluscio, S. Squinto, N. Y. IP, M. E. FurTh, R. M. LindSAY, AND G. D. YANCOPOULOS. 1990. NT-3, BDNF, and NGF in the developing rat nervous system:
Parallel as well as reciprocal patterns of expression, Neuron 5 : 501-509.

56. Martin-Zanca, D., M. Barbacid, and L. F. Parada. 1990. Expression of the trk proto-oncogene is restricted to the sensory cranial and spinal ganglia of the neural crest origin in the mouse. Genes Dev. 4: 683-694.

57. Martinou, J. C., A. Le Van Thai, G. Cassar, F. Roubinet, AND M. J. WEBER. 1989. Characterisation of two factors enhancing choline acetyltransferase activity in cultures of purified rat motoneurons. J. Neurosci. 9: 3645-3656.

58. Martinou, J. C., I. Martinou, and A. Kato. 1992. Cholinergic differentiation factor (CDF/LIF) promotes survival of isolated rat embryonic motoneurons in vitro. Neuron 8: 737-744.

59. Masiakowski, P., H. LiU, C. Radziejewski, F. LotTspeich, W. Oberthuer, V. Wong, R. M. Lindsay, M. E. Furth, and N. PANAYOTATOS. 1991. Recombinant human and rat ciliary neurotrophic factors. J. Neurochem. 57: 1003-1012.

60. Masu, Y., E. Wolf, B. Holtmann, M. Sendtner, G. Brem, AND H. THOENEN. 1993. Disruption of the CNTF gene results in progressive motoneuropathy. Nature 365: 27-32.

61. Messer, A., AND L. Flatherty. 1986. Autosomal dominance in a late-onset motor neuron disease in the mouse. $J$. Neurogenet. 3: 345-355.

62. Messer, A. 1992. Animal models of amyotrophic lateral sclerosis. In Handbook of Amyotrophic Lateral Sclerosis. (R. A. Smith, Ed)., pp. 433-452. Dekker, New York.

63. Meyer, M., I. Matsuoka, C. Wetmore, L. Olson, and H. THOENEN. 1992. Enhanced synthesis of brain-derived neurotrophic factor in the lesioned peripheral nerve: Different mechanisms are responsible for the regulation of BDNF and NGF mRNA. J. Cell Biol. 119: 45-54.

64. Mitchell, J. D., AND M. J. JACKson. 1992. Free radicals, amyotrophic lateral sclerosis, and neurodegenerative disease. In Handbook of Amyotrophic Lateral Sclerosis. (R. A. Smith, Ed.), pp. 533-542. Dekker, New York.

65. Mryata, Y., Y. Kashihara, S. Homma, and M. Kuno. 1986. Effects of nerve growth factor on the survival and synaptic function of 1a sensory neurons axotomized in neonatal rats. $J$. Neurosci. 6: 2012-2018.

66. Mulligan, R. C. 1993. The basic science of gene therapy. Science 260: 926-932.

67. Munsat, T. L., P. L. Andres, L. Finison, T. Conlon, and L. ThibodeaU. 1988. The natural history of motoneuron loss in amyotrophic lateral sclerosis. Neurology 38: 409-413.

68. Nichol, K. A., AND M. R. BENNETT. 1987. Motoneurone survival and neurite regeneration requirements: The role of dorsal root ganglion cells during development. Dev. Brain Res. 32: 85-94.

69. NiSHI, R., AND D. K. BERG. 1979. Survival and development of ciliary ganglion neurones grown alone in cell culture. Nature (London) 277: 232-234.

70. Nurcombe, V., N. G. Wreford, and J. F. Bertram. 1991. The use of the optical disector to estimate the total number of neurons in the developing chick lateral motor column: Effects of purified growth factors. Anat. Rec. 231: 416-424.

71. NurcomBE, V. 1993. FGF presented on a novel heparan sulfate prevents motor neurone cell death. Prog. Motor Neurone Dis. Res. [Meeting Abstract, Melbourne].

72. Nurcombe, V., M. Ford, J. A. Wildschut, AND P. F. BARTLETT. 1993. Developmental regulation of neural response to FGF-1 and FGF-2 by heparan sulfate proteoglycan. Science 260: 103-106.

73. O'BRIEN, R. J., AND G. D. FISCHBACH. 1986. Isolation of embryonic chick motoneurons and their survival in vitro. J. Neurosci. 6: 3265-3274. 
74. OPPENHEIM, R. W. 1986. The absence of significant postnatal motoneuron death in the brachial and lumbar spinal cord of the rat. J. Comp. Neurol. 246: 281-286.

75. Oppenheim, R. W., L. J. Haverkamp, D. Prevette, J. L. McManaman, AND S. H. Appel. 1988. Reduction of naturally occurring motoneuron death in vivo by a target-derived neurotrophic factor. Science 240: 919-921.

76. Oppenheim, R. W., D. Prevette, and F. Fuller. 1992. The lack of effect of basic and acidic fibroblast growth factors on the naturally occurring death of neurons in the chick embryo. J. Neurosci. 12(7): 2726-2734.

77. Oppenheim, R. W., D. Prevette, Y. Qin-Wei, F. Collins, AND J. MacDonald. 1991. Control of embryonic motoneuron survival in vivo by ciliary neurotrophic factor. Science $\mathbf{2 5 1}$ : 1616-1618.

78. Oppenheim, R. W., Y. Qin-Wei, D. Prevette, and Q. Yan. 1992. Brain-derived neurotrophic factor rescues developing avian motoneurons from cell death. Nature 360: 755-757.

79. OTTO, D., AND K. UNSICKER. 1990. Basic FGF reverses chemical and morphological deficits in the nigrostriatal system of MPTP-treated mice. J. Neurosci. 10: 1912-1921.

80. PATterson, P. H., AND M.-J. FANN. 1992. Further studies on the distribution of CDF/LIF mRNA. Ciba Found. Symp. 167: 125-140.

81. Piccioli, P., F. Ruberti, S. Biocca, A. Di Luzio, T. M. Werge, A. Bradbury, and A. Cattaneo. 1991. Neuroantibodies: Molecular cloning of a monoclonal antibody against substance $\mathrm{P}$ for expression in the central nervous system. Proc. Natl. Acad. Sci. USA 88: 5611-5615.

82. Pollin, M. M., S. McHanwell, and C. R. Slater. 1990. Loss of motor neurons from the median nerve motor nucleus of the mutant mouse "wobbler." J. Neurocytol. 19: 29-38.

83. Prosser, C. G., AND R. D. MCLAREN. 1992. Insulin-like growth factor binding proteins of equine serum. Biophys. Biochem. Res. Commun. 189: 1255-1260.

84. RAO, M. S., AND S. C. LANDIS. 1993. Cell interactions that determine sympathetic neuron transmitter phenotype and the neurokines that mediate them. J. Neurobiol. 24: 215-232.

85. Raz, E., A. Watanabe, S. M. Baird, R. A. Eisenberg, T. B. PARr, M. Lotz, T. J. KipPS, AND D. A. CARSON. 1993. Systemic immunological effects of cytokine genes injected into skeletal muscle. Proc. Natl. Acad. Sci. USA 90: 4523-4527.

86. Rende, M., D. Muir, E. Rouslathi, T. HagG, S. Varon, and M. MANTHORPE. 1992. Immunolocalization of ciliary neuronotrophic factor in adult rat sciatic nerve. Glia 5: 25-32.

87. Rosen, D. R., T. Siddique, D. Patterson, D. A. Figlewicz, P. Sapp, A. Hentati, D. Donaldson, J. Goto, J. P. O'Regan, H.-X. Deng, Z. Rahmani, A. Krizus, D. McKenna-Yasek, A. Cayabyab, S. M. Gaston, R. Berger, R. E. TAnzi, J. J. HalPerin, B. Herzfeldt, R. VAn den Berg, W.-Y. Hung, T. Bird, G. Deng, D. W. Mulder, C. Smyth, N. G. Laing, E. Soriano, M. A. Pericak-Vance, J. Haines, G. A. Rouleau, J. S. Gusella, H. R. Horvitz, ANd R. H. Brown JR. 1993. Mutation in $\mathrm{Cu} / \mathrm{Zn}$ superoxide dismutase gene are associated with familial amyotrophic lateral sclerosis. Nature 362: 59-62.

88. Rowland, L. P. 1991. Amyotrophic lateral sclerosis and other motor neuron diseases. Advances in Neurology Vol. 56. Raven Press, New York.

89. SChNAAR, R. L., AND A. E. SCHAFFNER. 1981. Separation of cell types from embryonic chicken and rat spinal cord: Characterization of motoneuron-enriched fractions. J. Neurosci. 7: 204217.

90. SchmalbruCh, H. 1984. Motoneuron death after sciatic nerve section in newborn rats. J. Comp. Neurol. 224: 252-258.
91. Schmalbruch, H., H. J. S. Jensen, M. Bjaerg, Z. KamienIECKA, AND L. KURLAND. 1991. A new mouse mutant with progressive motor neuronopathy. J. Neuropathol. Exp. Neurol. 50: 192-204.

92. Schooltink, H., T. Stoyan, E. Roeb, P. C. Heinrich, and S. RosE-JOHN. 1992. Ciliary neurotrophic factor induces acutephase protein expression in hepatocytes. FEBS Lett. 314 : 280284.

93. Sendtner, M., G. W. Kreutzberg, and H. Thoenen. 1990. Ciliary neurotrophic factor prevents the degeneration of motor neurons after axotomy. Nature 345: 440-441.

94. Sendtner, M., Y. Arakawa, K. A. Stöckli, G. Kreutzberg, AND H. THOENEN. 1991. Effect of ciliary neurotrophic factor (CNTF) on motoneuron survival. J. Cell Sci. Suppl. 15: 103109.

95. Sendtner, M., H. Schmalbruch, K. A. Stöckli, P. Carroll, G. W. Kreutzberg, And H. Thoenen. 1992. Ciliary neurotrophic factor prevents degeneration of motor neurons in mouse mutant progressive motor neuronopathy. Nature 358: 502-504.

96. Sendtner, M., B. Holtmann, R. Kolbeck, H. Thoenen, And Y.-A. BARDE. 1992. Brain-derived neurotrophic factor prevents the death of motoneurons in newborn rats after nerve section. Nature 360: 757-759.

97. Sendtner, M., K. A. Stöckli, And H. Thoenen. 1992. Synthesis and location of ciliary neurotrophic factor in the rat sciatic nerve of the adult rat after lesion and during regeneration. J. Cell Biol. 118: 139-148.

98. Sendtner, M., F. Dittrich, R. A. Hughes, and H. Thoenen. 1993. Actions of CNTF and neurotrophins on degenerating motoneurons: Preclinical studies and clinical implications. $J$. Neurol. Sci., in press.

99. Smith, R. G., J. McManaman, And S. H. Appel. 1985. Trophic effects of skeletal muscle extracts on ventral spinal cord neurons in vitro: Separation of a protein with morphologic activity from proteins with cholinergic activity. J. Cell Biol. 101: 16081621.

100. Stöckli, K. A., F. Lottspeich, M. Sendtner, P. MasiaKowski, P. Carroll, R. Götz, D. Lindholm, AND $\mathrm{H}$. THOENEN. 1989. Molecular cloning, expression and regional distribution of rat ciliary neurotrophic factor. Nature 342: 920 923.

101. Stöckli, K. A., L. E. Lillien, M. NÄher-Nó́, G. Breitffeld, R. A. Hughes, M. C. Raff, H. Thoenen, and M. Sendtner. 1991. Regional distribution, developmental changes, and cellular localization of CNTF-mRNA and protein in the rat brain. J. Cell Biol. 115: 447-459.

102. Swash, M., AND M. S. Schwartz. 1992. What do we really know about amyotrophic lateral sclerosis? J. Neurol. Sci. 113: 4-16.

103. TAgA, T., AND T. Kishimoto. 1992. Cytokine receptors and signal transduction. FASEB J. 6: 3387-3396.

104. Thoenen, H., And Y.-A. Barde. 1980. Physiology of nerve growth factor. Physiol. Rev. 60: 1284-1335.

105. Tollefsen, S. E., J. L. Sadow, and P. Rotwein. 1989. Coordinate expression of insulin-like growth factor II and its receptor during muscle differentiation. Proc. Natl. Acad. Sci. USA 86: 1543-1547.

106. Xu, Z., L. C. Cork, J. W. Griffin, and D. W. Cleveland. 1993. Increased expression of neurofilament subunit NF-L produces morphological alterations that resemble the pathology of human motor neuron disease. Cell 73: 23-33.

107. Yan, Q., J. ElliotT, AND W. D. SNider. 1992. Brain-derived neurotrophic factor rescues spinal motor neurons from axotomy-induced cell death. Nature 360: 753-755. 